\title{
El Congreso chileno y su aporte a la CONSOLIDACIÓN DEMOCRÁTICA EN PERSPECTIVA COM PARADA*
}

\author{
Detlef Nolte \\ Instituto de Estudios lberoamericanos, Universidad de Hamburgo, Alemania
}

\begin{abstract}
Resumen
El artículo enfoca la paradoja de que el sistema político chileno ha funcionado satisfactoriamente, a pesar de combinar rasgos que, según la literatura científica, deberían crear inestabilidad. Se lleva a cabo un análisis de las relaciones de poder entre el Congreso y el Presidente para esbozar los rasgos específicos de la separación horizontal de poderes en Chile, enfatizando, sobre todo, en los elementos que han contribuido a la estabilidad del sistema político. En la parte final, se discute desde un enfoque más amplio sobre el aporte específico del Congreso a la consolidación de la democracia chilena. Se concluye planteando que el parlamento ha logrado una institucionalización horizontal bastante exitosa, pero que en la percepción de los ciudadanos no ha logrado una institucionalización vertical satisfactoria.
\end{abstract}

\begin{abstract}
The article focuses on the paradox that the Chilean political system has funcioned satisfactorily despite the fact that it combines characteristics which in the scholarly literature are held to be leading to instability. On this background, the author analizes the relations of power between Congress and President, with special emphasis on those elements which have contributed to political stability. He then widens the focus to discuss the specific contributions the nation's Congress has made to the democratic consolidation of Chile. He concludes that the Chilean parliament has been quite sucessful in regard to horizontal institutionalization whereas -according to a widespread perception of Chile's citizens- it still shows many deficiencies in regard to its vertical institutionalization.
\end{abstract}

PALABRAS CLAVE • Chile • Congreso • Presidencialismo • Coalición • Consolidación Democrática

Para algunos politólogos, el sistema político chileno constituye una paradoja: funciona a pesar que entremezcla rasgos que, según la literatura científica, deberían crear inestabilidad². La preocupación reside sobre todo en la concentración de poderes en el ejecutivo y la fortaleza de su

* $\quad$ Agradezco las críticas y sugerencias de mis colegas Mariana Llanos y Francisco Sánchez. Las deficiencias y errores son responsabilidad exclusiva del autor.

2 En su mayoría, se trata de politólogos influidos por el debate iniciado por Juan Linz (1994; 1996a; 1996b) sobre los defectos de los sistemas presidenciales y las posibles virtudes de los sistemas parlamentarios. El problema principal consiste en que la democracia presidencial no conduce sistemáticamente a asegurar al Gobierno con una mayoría parlamentaria. De esta manera, existe el riesgo de un bloqueo recíproco entre el Presidente y el Congreso y de un inmovilismo político debido a mayorías no congruentes. Diferentes autores ven precisamente en este hecho el "talón de Aquiles" de los sistemas presidenciales (véase Mainwaring, 1993: 215). Esto vale de manera especial para las democracias presidenciales con sistemas de multipartidismo: a difficult combination (Mainwaring 1993). Los argumentos de Linz son aplicados al sistema político chileno especialmente por Arturo Valenzuela (1994) y su discípulo Peter Siavelis (1997; 2000a; 2002). 
presidencialismo en combinación con un sistema multipartidario que implica el riesgo de elegir presidentes con una base política-partidaria minoritaria en el electorado y en el Congreso. En base a esta constelación adversa, Peter Siavelis (2000a: XX), autor del estudio más amplio sobre el sistema político chileno en los años noventa publicado hasta ahora, plantea: "in many ways Chile is a country with perhaps the most problematic institutional structure in Latin America in terms of the findings of this study and those of the theorists discussed here".

A pesar del escepticismo de varios de los observadores, el sistema político chileno ha funcionado mucho mejor de lo pronosticado y el presidencialismo chileno acusa más estabilidad que otros sistemas similares en el continente. En la actualidad se considera a Chile como una de las democracias más desarrolladas ${ }^{3}$ y estables de América Latina. La pregunta es: ¿Cómo explicar esta contradicción entre la teoría y la realidad? Algunas de las respuestas aducen que este "buen funcionamiento" se debería a las circunstancias especiales de la transición, las cuales obligaron a todos los actores a transigir a favor del proyecto democrático y, sobre todo, dotaron a los presidentes del apoyo casi incondicional de los partidos de su coalición. Es la contingencia de esta situación lo que ha permitido a algunos investigadores seguir manteniendo los malos augurios sobre el futuro y advertir que los rasgos institucionales vistos como problemáticos pueden poner en peligro la estabilidad política. Con casi catorce años de funcionamiento continuo de las instituciones políticas básicas, como lo son el Congreso y la Presidencia, parece poco convincente explicar ese buen desenvolvimiento como resultado de circunstancias excepcionales. Tal vez sería más útil cambiar el enfoque de análisis para explicar el relativo "éxito" del sistema presidencial chileno.

El tema principal de este estudio es el aporte del Congreso al desarrollo y a la institucionalización de la democracia en Chile. En este sentido, presentaremos en primer lugar un breve resumen de las distintas visiones acerca del papel del Poder Legislativo antes y después de la dictadura, para después continuar con un análisis de las relaciones de poder con el Ejecutivo en la actualidad, algo necesario para ponderar el peso real del Congreso en un sistema presidencial. Esbozaremos los rasgos específicos de la separación horizontal de poderes en Chile, enfatizando, especialmente, en los elementos que han contribuido a la estabilidad del sistema político. En la parte final, discutiremos desde un enfoque más amplio sobre el aporte específico del Congreso a la consolidación de la democracia chilena.

\section{VISIONES DEL CONGRESO CHILENO Y LAS RELACIONES DE PODERES EN EL PASADO Y ELPRESENTE}

Revisando los textos básicos sobre los sistemas políticos en América Latina en general y el sistema político chileno en particular que fueron publicados antes del golpe militar, se puede concluir que hay un tópico recurrente: el Congreso chileno es descrito como un legislativo sumamente fuerte e influyente. Así, por ejemplo, Federico Gil (1966: 117-118) en su libro clásico sobre el sistema político chileno, publicado a mediados de los años sesenta, escribe: "Unlike many Latin American legislatures, the Chilean Congress is not a rubber-stamp body. It is an independent, properly elected, deliberative assembly, which often challenges the authority of the executive and participates actively in the determination of national policies". En un estudio comparativo sobre el papel y la influencia de los

Véase por ejemplo Altman y Pérez-Linán (2002) y las evaluaciones por parte de Freedom House (http:// www.fredomhouse.org). 
parlamentos latinoamericanos publicado al principio de los setenta, Weston Agor (1971b: xli) hace hincapié en que: "it appears clear that at least three Latin American Legislatures -Chile, Costa Rica, and Uruguay- exercise considerably more decision-making influence in the total political system than is typical of most world legislatures". Finalmente, en una retrospectiva hecha después de 1973, Arturo Valenzuela (1976: 16) describió el Congreso chileno de la siguiente manera: "Chile's legislature, which has now been closed by the military, was one of the strongest in the world, even though it no longer enjoyed the center of political life as it did at the turn of the century", y en otro trabajo elogio al parlamento como "a legislature which was arguably the most highly institutionalized in the entire underdeveloped world" (Valenzuela y Wilde, 1979: 191).

La explicación de la fortaleza del Congreso de Chile dada por Valenzuela y Wilde (1979) gira en torno a la experiencia acumulada durante la República Parlamentaria (1891-1924)'AEn este período echaron raíces prácticas parlamentarias que se conservaron después y que convirtieron al Congreso en un foro para forjar compromisos políticos de apoyos a los presidentes minoritarios basándose en una política clientelar y particularista que, a su vez, funcionaba como contrapeso y factor estabilizador en un sistema multipartidario polarizado.

Sin embargo, ya a mediados de los sesenta, se percibía un proceso de declive del Congreso, cuyo punto culminante fue el de las reformas constitucionales de 1970 con las que éste perdió protagonismo como resultado de un enfoque político mucho más tecnocrático que trató de eliminar los elementos particularistas en la política y que concentró más poder en el presidente, especialmente en el proceso legislativo y en materias presupuestarias. Si se mira retrospectivamente, el comentario oficialista que hizo el entonces mandatario Eduardo Frei (1970) con algunos de sus ministros y colaboradores más estrechos sobre los alcances de la reforma constitucional, llama la atención los elogios sobre las bondades de la iniciativa exclusiva del Ejecutivo en muchas materias, la delegación de facultades legislativas al Presidente y la aceleración de los trámites legislativos por parte del Poder Ejecutivo. Solamente nueve años más tarde, Arturo Valenzuela y Alexander Wilde (1979: 204/211-213) interpretan los resultados de la reforma constitucional de una manera muy distinta:

Congress had been dealt a severe blow by constitutional reforms adopted before Allende's election in the closing days of the Frei administration. ... It would be a serious oversimplification to argue that the reduction of the role of Congress led to the breakdown of Chilean democracy ... When congressional politicians lost the capacity to deliver concrete favors, they lost ground within the party organizations to other elites who traded in more symbolic currencies. When Congress lost its particularistic functions, the territorial cleavages that cut across the system lost salience and were overwhelmed by those along more economic lines, above all the cleavage of class.

Muchos de los elementos de la reforma constitucional de 1970 que cambiaron de una manera profunda el equilibrio de poderes entre el Presidente y el Congreso en el proceso legislativo influyeron también en la constitución pinochetista de 1980. Nos parece importante subrayar de que muchas atribuciones presidenciales que reforzaron su preponderancia frente al Congreso, y que todavía dominan en los análisis del sistema político vigente, se remontan al período de antes del golpe de Estado. Como resultado de tales reformas -según el estudio clásico de Carey y Shugart (1992: 155) sobre presidentes y asambleas-, el presidente chileno tenía los poderes legislativos 
más amplios del total de 44 casos incluidos en el análisis. Los poderes legislativos del presidente en 1970 fueron clasificados como mucho más fuertes que sus facultades en la Constitución de 1980 , incluyendo las reformas de $1989^{4}$. Con ese trasfondo no es de extrañar que en el estudio de Weston Agor sobre el Senado chileno, publicado en 1971, se encuentre un párrafo sobre "los poderes formidables del presidente" que en algunos aspectos se podría mantener al hablar sobre el orden institucional actual:

the president may classify certain legislation urgent, thereby setting a time limit in which Congress must pass the bill. He also has 'exclusive' areas of initiative-for example, in proposing the annual budget-and Congress is supposedly limited to reducing the requested expenditures of funds. Congress may also grant extraordinary powers to the executive in emergency situations, and he has wide veto powers (Agor, 1971a: 7).

Si se hace un análisis de la literatura científica después del retorno a la democracia, la evaluación del Congreso chileno y de todo el sistema político es totalmente diferente a los análisis predominantes en los años sesenta y setenta anteriormente citados. Así, por ejemplo, Peter Siavelis (2000a: 2) postula que "The 1980 constitution provides for the weakest Congress of any period in Chile's modern political history".

\section{UN PRESIDENCIALISMO FUERTE, PERO CON LÍMITES}

Cambiando el eje y dejando de lado el análisis diacrónico, cabría preguntarse sobre la correlación de poderes entre el Legislativo y el Ejecutivo en perspectiva comparada con los otros sistemas políticos latinoamericanos.

La relación de poder entre el Presidente y el Parlamento se puede analizar desde dos ángulos: desde el punto de vista del Presidente, como lo hacen en la mayoría de los estudios (Shugart y Carey, 1992; Mainwaring y Shugart, 1997; Metcalf, 2000; Shugart y Haggard, 2001; Payne et al., 2002), o desde el punto de vista del Parlamento (Krumwiede y Nolte, 2000). Los indicadores utilizados son, en gran parte, los mismos; sin embargo, presentan variaciones en cuanto a su ponderación. A continuación presentamos una síntesis de los poderes relativos del presidente y del Congreso chileno en base a los enfoques comparativos que fueron desarrollados en los años ‘90 y aplicados a los sistemas políticos de América Latina.

Los poderes comprendidos en la interacción entre Presidente y Parlamento se pueden distinguir de forma general entre poderes legislativos y no legislativos (Shugart y Carey, 1992: 155; Metcalf, 2000: 669-670; Payne et. al., 2003: 197-222). Los últimos abarcan las facultades del presidente

Como bien señala Siavelis (2000a: 15), el análisis de la Constitución de 1980/89 que hacen Shugart y Carey (1992) incluye algunos errores, que él procura corregir. No obstante, las modificaciones que Siavelis (2000a: 15) efectúa no afectan el orden en que se clasificaron las constituciones según los poderes legislativos del presidente. Por ello, la Constitución de 1970 conserva su rango como la más presidencialista en el área de los poderes legislativos. Respecto a los poderes no legislativos -según Carey y Shugart (1992: 155)- la Constitución de 1980/89 otorga más poderes al presidente que la constitución vigente en 1970. De todos modos, en nuestra opinión, los autores cometieron otro error de cálculo al incluir entre las atribuciones del Presidente, la disolución del Congreso, que fue eliminada con las reformas de 1989. Así, con las correcciones respectivas, los poderes no-legislativos del presidente en la constitución actual son iguales a la vigente antes del golpe de Estado. 
con respecto a la integración y destitución del Gabinete o la posibilidad de censura o de un voto de desconfianza a los miembros del ejecutivo por parte del Parlamento. Comparando dentro de este ámbito a Chile con los otros países latinoamericanos, se puede decir que cuenta con un presidente muy fuerte y un parlamento muy débil, porque no existe la posibilidad de un voto de censura, ni la alternativa de destituir a un ministro 0 al gabinete (Payne et al., 2002: 218; Krumwiede y Nolte, 2000: 77). Pero estas restricciones al poder parlamentario son propias de la lógica de un sistema presidencial "puro" y en principio no deberían debilitarlo, porque sus poderes radican en otros aspectos.

Siguiendo con el tema de los poderes no legislativos, cabe mencionar también la declaración del estado de sitio o de emergencia y las competencias del Presidente para nombrar libremente o con aprobación legislativa a jueces u otras autoridades de control, embajadores, o dictaminar ascensos a altos cargos militares. Estos últimos aspectos muestran diferencias considerables entre los sistemas políticos latinoamericanos (Krumwiede y Nolte, 2000: 77). De hecho, el presidente chileno está menos restringido y controlado por el Congreso en estas áreas que la mayoría de sus pares latinoamericanos ${ }^{5}$.

La distribución de poder en el proceso legislativo es de importancia central para entender la correlación de poderes entre el Presidente y el Parlamento. Las competencias legislativas del Presidente se pueden diferenciar con relación al status quo legislativo en "poderes reactivos", es decir, competencias que defienden ese equilibrio frente a las decisiones e iniciativas del Parlamento; y "poderes proactivos", con los cuales los presidentes pueden asumir la iniciativa legislativa y condicionar las posibilidades de reacción del Parlamento (Mainwaring y Shugart, 1997: 41-48). Entre los primeros se encuentra el poder exclusivo del Dignatario de iniciativa con respecto a determinadas materias legales, por lo general, en asuntos presupuestarios o leyes relacionadas con los gastos del Estado. Esta facultad es percibida por Shugart y Mainwaring (1997: 48) como un poder reactivo, ya que permite al Presidente conservar el statu quo económico presupuestario, a la vez que le protege del riesgo de mayorías legislativas adversas, en especial las que pueden resistir un veto presidencial. La ventaja que otorga al Gobernante es que puede bloquear cualquier cambio por el solo hecho de negarse a introducir leyes en las áreas de su iniciativa exclusiva. Por eso algunos autores (Shugart y Haggard, 2001: 77) hablan del "poder de cuidar la puerta" (gatekeeping).

Pero la facultad reactiva más importante del Presidente es el veto frente a decisiones del Parlamento en el proceso legislativo. En Chile, al igual que en Argentina y Bolivia, el veto puede ser insistido por una mayoría especial de dos terceras partes de los parlamentarios presentes. A diferencia de Estados Unidos, prototipo del sistema presidencial, y de Ecuador, Panamá y República Dominicana, donde un veto del Presidente sólo puede ser rechazado por una mayoría de las dos terceras partes de todos los parlamentarios y en ambas cámaras en los casos bicamerales. En Brasil, Colombia, Nicaragua, Paraguay y Perú basta la mayoría absoluta de todos los parlamentarios; mientras que en Uruguay hacen falta las tres quintas partes de todos los presentes en cada

Con la importante excepción del nombramiento de la cúpula militar. En ese caso, los poderes del Presidente no se restringuen por la interacción con el Poder Legislativo, sino por las atribuciones propias de las Fuerzas Armadas ancladas en la Constitución y en las leyes orgánicas. 
una de las dos cámaras. La Constitución venezolana de 1999, al igual que la anterior de 1961, sólo exige una mayoría simple de los parlamentarios presentes.

Por consiguiente, si se toma en cuenta el reparto de atribuciones en los otros países, Chile se encontraría entre aquellos países donde el Presidente cuenta con poderes reactivos muy amplios en el proceso legislativo, que incluyen tanto el poder de iniciativa exclusiva como el veto fuerte. Asimismo, el Gobernante puede vetar solamente una parte de una ley, pero no cuenta con un veto parcial (o ítem veto) en el sentido estricto de poder promulgar las partes de la ley que no fueron vetadas $^{6}$.

Entre los poderes proactivos está el derecho presidencial de promulgar decretos-leyes sobre determinados asuntos, dentro de lo que hay que distinguir entre los poderes propios del Presidente, aquellos que la Constitución le otorga, y los que le son delegados por el Parlamento (véase Carey y Shugart, 1998: 12-14). Al considerar todos los países latinoamericanos, se detecta claramente que sólo una minoría de las Constituciones reconoce a los Presidentes derechos propios 0 delegados para emitir decretos-leyes. No obstante, debe admitirse que en la clasificación de los poderes de decreto en los diferentes constituciones latinoamericanas, según la literatura relevante, existen contradicciones y una amplia variación que tiene que ver con criterios de interpretación divergentes. Parece que en el caso de los poderes de legislar por decreto (pero también respecto a otros poderes del Presidente) no es posible limitarse solamente a los textos constitucionales sin tomar en cuenta la praxis constitucional. En caso contrario, existiría el riesgo de una interpretación errónea de la realidad política en algunos países ${ }^{7}$.

Según la interpretación que hicimos en un trabajo anterior (Krumwiede y Nolte, 2000: 77-79, 8486), a fines de la década de 1990, sólo en siete de los dieciocho Estados latinoamericanos, los presidentes tenían poderes propios o delegados para promulgar decretos-leyes, incluyendo entre los "países decreto" dos casos ambiguos (Panamá y Honduras) que normalmente no son incluidos entre los países con un amplio poder de decreto (ver Shugart y Carey, 1992; Mainwaring y Shugart, 1997; Shugard y Haggard, 2001: 80). En Chile ${ }^{8}$ y Venezuela ${ }^{9}$, por su parte, el Presidente sola-

En eso están de acuerdo casi todos los estudios comparativos (véase Shugart y Carey, 1992: 155; Mainwaring y Shugart, 1997: 43-44; Shugart y Haggard, 2001: 80; Morgenstern, 2002: 438; Siavelis, 2002: 19), por eso nos parece erróneo la clasificación en el libro de Payne et al. (2003: 216).

7 Un buen ejemplo es lo ocurrido en la Argentina, cuyo ex presidente, Carlos Menem, hizo uso de la legislación por decreto y el veto parcial aunque no estaban contemplados en la constitución argentina de 1853. Es por ello que según la clasificación de Shugart y Carey (1992: 155) el presidente argentino tenía muy pocos poderes legislativos, sin duda una apreciación que nada tiene que ver con la realidad argentina, tal y como lo han demostrado trabajos como los de Ferreira Rubio (1998) o Mustapic (2002).

8 Con referencia al artículo 32 literal 22 de la constitución, Carey y Shugart (1998: 10, 279) caracterizan a Chile como un sistema presidencial que reconoce al presidente derechos propios para emitir decretos-ley. El artículo mencionado estipula: "El Presidente de la República, con la firma de todos los Ministros de Estado, podrá decretar pagos no autorizados por ley, para atender necesidades impostergables derivadas de calamidades públicas, de agresión exterior, de conmoción interna, de grave daño o peligro para la seguridad nacional o del agotamiento de los recursos destinados a mantener servicios que no puedan paralizarse sin serio perjuicio para el país. El total de los giros que se hagan con estos objetos no podrá exceder anualmente del dos por ciento (2\%) del monto de los gastos que autorice la Ley de Presupuesto." La clasificación de Carey y Shugart (1998), retomada en Payne et al (2003: 309) y Negretto (2003: 59/ 61) no nos convence porque ese tipo de decreto no es comparable con los decretos leyes que fueron usados en Argentina, Brasil y Perú para llevar a cabo reformas políticas importantes. 
mente puede ejercer facultades para emitir decretos-leyes si éstas le han sido otorgadas expresamente por el Parlamento. Sólo en tres países, Brasil, Perú y Argentina ${ }^{10}$, el Presidente posee facultades propias para emitir decretos, inicialmente previstas según la Constitución para decisiones urgentes en situaciones de excepción, pero que en los países mencionados se han convertido en un proceso normal de legislación. Colombia constituye un caso especial en cuanto el Mandatario se podría apropiar de facultades para dictar decretos-leyes por medio de la declaración del estado de emergencia.

Es necesario ponderar los diferentes poderes reactivos y proactivos que disponen los presidentes, porque algunos determinan más que otros las relaciones entre el Presidente y el Parlamento. En ese contexto, la facultad de emitir decretos-leyes como derecho constitucional propio es sobresaliente. Hay que recordar que la crítica frente a la omnipotencia presidencial en forma de un "hiperpresidencialismo" o "presidencialismo hipertrofiado" -según las palabras del constitucionalista argentino Carlos Nino (1992)- o de una "democracia delegativa" (O‘Donnell, 1992) en los sistemas presidenciales de América Latina se originó en los años noventa, ello sobre todo porque en algunos países se percibía que los presidentes gobernaban sin tener en cuenta a los parlamentos gracias a los decretos-leyes.

Partiendo de la distribución de competencias entre el Presidente y el Parlamento, sobre todo en el proceso legislativo, varios autores han intentado establecer un orden jerárquico de las constituciones latinoamericanas, cuyas clasificaciones presentan amplias coincidencias (ver Carey y Shugart, 1992: 155; Mainwaring y Shugart, 1997: 49; Krumwiede y Nolte, 2000: 77; Shugart y Haggard, 2001; Payne et al., 2003; Samuels y Shugart, 2003). Así, por ejemplo, si uno se limita a las competencias de dictar decretos-leyes, el derecho de veto y la iniciativa legislativa exclusiva del Gobernante, se encuentra que Argentina, Brasil, Chile, Ecuador, Colombia y Perú disponen de constituciones que le otorgan a éste una posición muy fuerte frente al Parlamento. En cambio, las constituciones de Bolivia, México, Paraguay, Uruguay y Venezuela les otorgan menos competencias a sus presidentes; lo mismo vale también para las Constituciones de América Central.

Las clasificaciones del sistema político chileno se diferencian solamente en matices, a saber:

- $\quad$ Shugart y Mainwaring (1997: 49) clasifican a Chile respecto a los poderes legislativos del presidente según la constitución como ejemplo sobresaliente de un presidente "potencialmente dominante".

- Krumwiede y Nolte (2000: 77) en su estudio sobre los poderes del parlamento en el proceso legislativo ponen a Chile en el noveno lugar (en un orden descendente según las atribuciones de los parlamentos) entre once constituciones latinoamericanos analizadas y lo toman como ejemplo de un parlamento con poderes bastante limitados.

- $\quad$ Shugart y Haggard (2001: 80) evalúan los poderes presidenciales en el proceso legislativo como muy altos, y ubican a Chile (junto con otros cinco países) en el tercer lugar (entre 23 casos analizados). 
- $\quad$ Samuels y Shugart (2003: 43) clasifican a Chile como un sistema presidencial con amplios poderes de veto y de agenda. Según los autores, en la actualidad en América Latina solamente los presidentes de Argentina y Ecuador cuentan con más poderes.

- $\quad$ Mark Payne y sus coautores (2003: 217) tipifican a Chile como un sistema presidencial en el cual el presidente cuenta con amplios poderes de reacción y moderados poderes de acción.

Nos inclinamos por la categorización de Payne et al. (2003), a pesar de estar en desacuerdo con algunos criterios y decisiones con los que construyen su caracterización. Los poderes de acción son restringidos por falta de poderes de decreto propios del Presidente, es decir, no delegados por el Legislativo, pero también por el hecho que muchas leyes necesitan un quórum especial de apoyo parlamentario que dificulta un cambio del status quo desde la perspectiva del presidente.

Hasta ahora nos hemos referido a autores y a conceptos de análisis hasta cierto punto predominantes que enfocan las relaciones entre el Parlamento y el Poder Ejecutivo desde una perspectiva de suma cero: si las atribuciones del Presidente aumentan, disminuyen los poderes del Parlamento. El Congreso y el Dignatario son vistos como actores opuestos entre sí sin que tengan necesidad de coordinar sus acciones. Además, según la lógica tradicional de la separación de poderes o checks and balances, el Congreso es percibido como un actor homogéneo y unitario. Nos gustaría cambiar este enfoque y considerar algunos de los poderes del Presidente como mecanismos que estructuran y facilitan la cooperación necesaria entre el Gobernante y su base de apoyo en el Parlamento.

Nos basaremos ahora en los autores brasileños Limongi y Figueiredo (1998: 86) que figuran entre los primeros que enfocaron de una manera más amplia y a la vez diferente los poderes de los presidentes latinoamericanos. Para ellos, uno de los más importantes es el "poder de agenda" del presidente y que se refiere a la capacidad que éste tiene para determinar cuáles propuestas son consideradas en el Parlamento y cuándo son consideradas. Un mayor poder de agenda implica, según los autores, la capacidad del Ejecutivo de influir de manera directa en el trabajo legislativo y de mitigar los efectos de la separación de poderes.

Desde esta perspectiva es posible interpretar las facultades de algunos presidentes de legislar por decreto de otra manera. Por un lado, no es un poder absoluto. Hay que tener en cuenta que como regla general los decretos dictados por el Presidente podrán ser derogados o modificados en cualquier momento por el Parlamento. Es verdad que con frecuencia se puede observar cierta tendencia hacia el abuso en aquellos países cuya Constitución le otorga al Presidente la posibilidad de dictar decretos-ley. Sin embargo, el hecho que presidentes que disponían de una mayoría parlamentaria o que sabían que por regla general podían contar con mayorías legislativas también recurrieron a la posibilidad de dictar decretos-ley, hace pensar que estos instrumentos son utilizados con el fin de dirigir o acelerar el proceso legislativo. El decreto-ley debe ser analizado, por tanto, en el contexto de otros mecanismos con una función comparable.

Aparte de la legislación por decreto y de las competencias exclusivas del Mandatario para tomar la iniciativa legislativa en ciertas áreas, que otros autores ven como parte de los poderes reactivos del Presidente (Shugart y Mainwaring, 1997: 48), al "poder de agenda" pertenece también la capacidad del Presidente de determinar las prioridades en el trabajo parlamentario. Enmarcando 
el caso de este trabajo dentro de los conceptos arriba citados, se puede afirmar que la facultad de agenda del presidente en Chile es bastante amplia. Así, por ejemplo, la Constitución chilena le otorga al Presidente el derecho exclusivo de tomar la iniciativa legislativa en todos los campos relacionados con la política financiera del Estado (impuestos, gastos, préstamos, etc.), salarios mínimos y contratos colectivos, sistemas de seguridad social, administración estatal 0 estructuración territorial. Además, puede en cualquier fase del proceso legislativo -y esto vale para todas las leyes- exigir la deliberación urgente, en tres grados: simple urgencia, suma urgencia y discusión inmediata. Según el grado de urgencia, a la Cámara respectiva le quedan treinta, diez o tres días para la discusión y votación del correspondiente proyecto de ley.

No hay que sobrevaluar el poder que dan las urgencias al Gobernante en comparación con otros mecanismos como la posibilidad de legislar por decreto (sin una autorización previa del Congreso), ya que está claro que la intervención del legislativo es más activa en el primer caso que en el segundo, tornando a la urgencia en un instrumento de menos fuerza para el presidente. En el caso de los decretos-leyes, como en Argentina o Brasil, un presidente actúa y cambia el status quo legislativo y si el parlamento no da un voto negativo de rechazo su posición prevalece. En la situación de las urgencias, el presidente necesita un voto positivo del parlamento para convertir su propuesta en ley teniendo siempre la posibilidad de rechazar el proyecto. Por eso, el presidente solamente puede usar esta facultad cuando tiene cierta certeza de contar con una mayoría parlamentaria suficiente.

Además, la importancia práctica de la urgencia es restringida porque el Presidente no cuenta con un instrumento de sanción si el parlamento no cumple con los limites de tiempo de las urgencias, porque sus iniciativas no se convierten en ley si el parlamento no las aprueba. La incapacidad del presidente de dominar por completo la agenda parlamentaria se refleja en las estadísticas legislativas; así, durante la presidencia de Patricio Aylwin (1990-1993), un porcentaje importante de proyectos de ley no cumplió con los plazos previstos, en especial al tratarse de urgencias simples (alrededor del $80 \%$ ). En el caso de la urgencia de discusión inmediata -sumando las cifras del primer y segundo trámite-, en más de un $20 \%$ no se cumplió con el plazo de tres días para la discusión y votación de los proyectos de ley (Siavelis, 2002: 96).

Hay que subrayar que el éxito de los proyectos de ley del presidente chileno depende en primera instancia, y a fin de cuentas, de la mayoría parlamentaria con la que cuenta. Durante el gobierno del presidente Aylwin, el tiempo promedio del trámite legislativo de los proyectos de ley que tenían urgencia no distó mucho de los proyectos que no la tenían. Tampoco hubo casi diferencia entre la tasa de éxito de las iniciativas legislativas presidenciales con y sin urgencia (sumando los diferentes grados de urgencia). La urgencia es un instrumento para señalar prioridades y organizar el trabajo parlamentario. En este sentido sí parece funcionar, ya que la tasa de éxito de las iniciativas presidenciales aumentó de acuerdo al grado de urgencia con que fueron calificados los mismos.

Se puede afirmar también que el trabajo legislativo funciona en Chile casi según la misma lógica que en un sistema parlamentario, donde el gobierno y los partidos que lo respaldan, que cuentan con una mayoría estable por lo menos en una cámara, coordinan estrechamente sus acciones, mientras que la minoría parlamentaria cumple con el rol de oposición. En este contexto, el poder 
de agenda del Presidente no es, de ninguna manera, un elemento extraño, sino que cumple con las exigencias de un gobierno estable en un sistema presidencial que funciona sobre la base de coaliciones de partidos con mayoría o casi mayoría en el parlamento.

Desde una perspectiva más general, los "poderes de agenda" acercan a los presidentes latinoamericanos a los jefes de gobierno en sistemas parlamentarios ${ }^{11}$ y diferencian al presidencialismo latinoamericano del sistema presidencial norteamericano, un hecho que fue muy bien elaborado por Cox y Morgenstern (2002: 463-465). En contraste con el ejecutivo norteamericano, los presidentes de América Latina tienen mucho más influencia en el trabajo parlamentario. Ellos pueden introducir leyes -y normalmente la mayoría de las leyes son iniciadas por el Poder Ejecutivo- y pueden influir en la agenda de trabajo del Parlamento ${ }^{12}$.

\section{SISTEMA MULTIPARTIDISTA Y PRESIDENCIALISMO DE COALICIÓN}

El poder de acción de un presidente no depende exclusivamente de sus poderes constitucionales, sino también del respaldo político que él y su partido han recibido en las elecciones, lo que a su vez se manifiesta en la composición del Congreso. Mainwaring y Shugart (1997: 41) han denominado este apoyo electoral-partidario "partisan power". En consecuencia, para una mejor percepción de la fortaleza del presidente dentro del sistema político hay que considerar la correlación de fuerzas entre estos dos campos, puesto que un presidente puede ser fuerte según sus poderes constitucionales y débil en su "partisan power", o viceversa.

El sistema político chileno, como muchos otros de América Latina, funciona en base a un sistema multipartidista que hace poco probable que un candidato presidencial pueda llegar a la presidencia con el respaldo de su propio partido únicamente y que a la vez ese partido tenga la mayoría en el Congreso. Ya hicimos hincapié (ver nota 2) en la discusión planteada por Linz (1994; 1996a; 1996b) y Valenzuela (1993) y reflejada también en la obra de Mainwaring y Shugart (1997) sobre los riesgos de un presidente de "doble minoría" confrontado con un Congreso de mayoría adversa: el temible "gobierno dividido" y su riesgo implícito de un bloqueo mutuo $0^{13}$ o "gridlock".

Pero parece que ese "problema" en la práctica política es mucho menos complicado que en la teoría, pero hasta cierto punto la teoría, o sus generadores, se niega a aceptar la realidad. Los arreglos institucionales funcionan sin duda como factores estructurantes para el comportamiento de los actores políticos, pero hay que tomar en cuenta a los actores políticos reales, cuyo compor-

Desde esta perspectiva resultaría interesante comparar los poderes de agenda de los presidentes latinoamericanos con los poderes de agenda de los gobiernos parlamentarios de Europa. Ya existen instrumentos probados para llevar a cabo tal investigación, como se puede ver en los trabajos de Döring (1995 y 2001) o Tsebelis (2002: 100-104).

12 Según Cox y Morgenstern (2002: 464), los sistemas presidenciales norteamericano y latinoamericanos en lo tocante a la relación entre el Ejecutivo y el Legislativo, se diferencian, ante todo, en las siguientes características: "(1) ministers cannot sit in the Assembly in the U.S. and typically are not appointed with an eye to building Assembly support, whereas they can often sit in the Assembly (practically speaking) in Latin America and are often appointed with an eye to solidifying assembly support; (2) ministers and the president wield important power in setting the assembly's internal legislative agenda in Latin America but not in the U.S.; and (3) the integration of the executive and legislative branches of the parties is often greater in Latin America (e.g. Costa Rica, Uruguay, and Venezuela) than in the United States."

13 Ver por ejemplo el índice de bloqueo político del BID (2000: 204) en el cual Chile recibe un valor muy alto. 
tamiento depende también de otros factores contingentes. En nuestro caso, el aprendizaje histórico, por ejemplo ${ }^{14}$.

Además, tiene sentido diferenciar entre las reglas básicas escritas y codificadas de un sistema político y las "reglas" derivadas o implícitas con las cuales los actores tienen que cumplir para que el sistema pueda funcionar. Ambas son igual de importantes. El proceso de apropiarse de las "reglas implícitas" y alcanzar una cierta rutina en su aplicación forma parte de la institucionalización de un sistema político. Dentro de esta perspectiva, las críticas o advertencias hacia un presidencialismo que se combina con un sistema multipartidario se refieren a una constelación en la cual los actores principales o no cumplen con las reglas básicas o no se someten a las reglas implícitas, lo que puede pasar en cualquier sistema político.

Un análisis detallado del modo como funcionaron las democracias presidenciales latinoamericanas en los años noventa muestra que en circunstancias en las cuales el partido del presidente no contaba con una mayoría, existían mecanismos para superar esta potencial situación de crisis. Ya que "la capacidad funcional de los sistemas presidencialistas en Latinoamérica no depende en primera línea de si los presidentes disponen de una mayoría parlamentaria de su propio partido 0 no. El aspecto decisivo es más bien que la formación del gobierno y la actividad gubernamental tengan en cuenta las relaciones de mayoría en el Parlamento" (Thibaut 1998: 149).

En un sistema multipartidario con escasa posibilidad de que un solo partido gane la presidencia y logre una mayoría parlamentaria, la formación de una coalición de gobierno es el único camino para dar cierta estabilidad al sistema político y garantizar la gobernabilidad (véase Foweraker et al., 2003: 117-118). Estamos de acuerdo con el argumento de Daniel Chasquetti (2002: 89): "La combinación de presidencialismo y multipartidismo es una combinación político-institucional apta para la democracia, siempre y cuando sus presidentes sean capaces de conformar coaliciones de gobierno de carácter mayoritario". En la realidad política latinoamericana de los años noventa y también en periodos anteriores hay amplios ejemplos de coaliciones de gobierno ${ }^{15}$. No todas fueron exitosas, pero existen suficientes pruebas que demuestran que la combinación de un presidencialismo con un gobierno de coalición puede funcionar, a pesar que muchos autores todavía se niegan a aceptar este hecho ${ }^{16}$.

En Chile, como en otros países de América Latina, se ha conformado o más bien reinstaurado un "presidencialismo de coalición", según un concepto acuñado por autores brasileños (Abranches, 1988; Limongi y Figuereido, 1998), más tarde retomado por Jorge Lanzaro (1998: 207-208) para

14

15

En ese sentido abogamos por un enfoque histórico-empírico, como fue denominado por Dieter Nohlen (2003).

Estadísticas sobre la importancia y el porcentaje de coaliciones electorales y de gobierno en América Latina se encuentran en Deheza (1998); Chasquetti (2002); Payne et al. (2003: 222-229).

Esta vacilación de armonizar las opiniones científicas preconcebidas de manera deductiva con la realidad empírica se ve también en el libro de Payne et al. (2003: 224, 232) cuando los autores evitan una clara definición: "En el marco del presidencialismo las coaliciones por lo general no llegan a formalizarse, así como tampoco son duraderas ni vinculantes para los legisladores, como ocurre en los sistemas parlamentarios. ... Pese a ello, las coaliciones constituyen un medio potencial para superar, al menos en forma parcial, el estancamiento que podría resultar de que el presidente tenga una base de apoyo partidista insuficiente en el Congreso. ... Sin embargo, se requieren estudios más detallados que permitan determinar la viabilidad general de las coaliciones para aliviar los problemas de gobernabilidad en regímenes presidencialistas y multipartidistas." 
describir la realidad uruguaya ${ }^{17}$ y también usado por Cox y Morgenstern (2002) en su comparación de diferentes tipos de presidencialismo y relaciones ejecutivos-legislativos en Latinoamérica. Estamos de acuerdo con Payne et al. (2003: 232) en que "esta modalidad en cierta forma parlamentarista dentro del presidencialismo ha mejorado la eficacia gubernamental". En los presidencialismos de coalición son mitigados los poderes presidenciales ${ }^{18}$. Si el Presidente no actúa con una visión más pluralista en el proceso de toma de decisiones, pone en peligro a la coalición que le sostiene ${ }^{19}$.

Para que funcione un presidencialismo de coalición son necesarias estructuras formales e informales que den sostén a ese arreglo institucional. Estas estructuras explican en parte el éxito y el fracaso de ese modelo presidencial en América Latina. Entre los logros hay que mencionar a Brasil, Uruguay, Chile y Bolivia; entre los fracasos hay que incluir el caso argentino durante el gobierno de la Alianza o el de Ecuador y sus crisis de gobierno que han llegado al extremo de convertirse en crisis de régimen.

A pesar de los avances en el tema de las coaliciones en los presidencialismos latinoamericanos, hasta ahora no han sido estudiados de manera suficiente los mecanismos institucionales que fortalecen estas alianzas. Sin embargo, para el caso chileno es posible enumerar algunos factores que favorecen la formación de coaliciones, que aumentan la cohesión entre los partidos miembros de la coalición y que facilitan la coordinación entre el poder ejecutivo presidencial y su base de sustento multipartidario:

- $\quad$ El sistema electoral de mayoría absoluta, ballotage para las elecciones presidenciales y distrito binominal para las elecciones parlamentarias, genera fuertes incentivos para que se forjen coaliciones electorales como base de futuras alianzas gubernamentales.

- $\quad$ Existe un sistema de compensaciones a través de cargos en el gobierno, sobre todo en las listas de la Concertación para los políticos de relevancia que son "sacrificados" al colocarles en distritos o posiciones en las listas en los que por la mecánica electoral resulta complicado salir electo (veáse Carey y Siavelis, 2003).

- Las coaliciones no corresponden solamente a cálculos electorales, sino que se basan en un programa de gobierno común y consensuado.

- Existe una coordinación del trabajo en el Congreso entre los parlamentarios de los diferentes partidos que forman la coalición. Esto se refleja en la composición de las mesas parlamentarias, las presidencias y los integrantes de las comisiones y en la votación (generalmente muy cohesionada) de las bancadas miembros de la alianza (véase Carey, 2002).

Sobre el caso uruguayo y algunas implicaciones generales para el análisis de coaliciones en sistemas presidenciales véase también Altman (2000).

18 Respecto al caso chileno véase Fernández (1998: 42).

19 No es nuestra intención profundizar sobre las diferencias entre coaliciones en sistemas parlamentarios y sistemas presidenciales. Son dos las diferencias principales: en un sistema presidencial el jefe del gobierno (presidente) no puede ser destituido (salvo en circunstancias excepcionales de un impeachement) sí su coalición se desintegra o pierde la mayoria parlamentaria; además el Presidente siempre cumple con la función del "formator" principal de la coalición (véase Nolte, 1998: 18-23; Altman, 2000: 260). 
- $\quad$ Los cargos ministeriales se dividen entre los partidos miembros de la coalición tomando en cuenta su aporte electoral. Además, se integra a representantes de otros partidos integrantes en cargos de segundo orden, como los subsecretarios, para evitar feudos partidarios y a la vez fomentar el espíritu de alianza ${ }^{20}$.

- La coordinación del trabajo del gabinete de coalición mediante la secretaría de presidencia (véase Rehren 1993; Drago 2002). Coordinación que se extiende a las relaciones entre el ejecutivo y los partidos/ bancadas del pacto a través de reuniones regulares con los líderes de las bancadas o partidos políticos.

En un presidencialismo de coalición, que se acerca a la lógica parlamentaria de una fusión parcial entre el gobierno y la mayoría parlamentaria, por un lado, y la oposición en el Congreso, por el otro, no sería necesario ampliar la participación del parlamento en su conjunto en la nominación y remoción de los ministros de gabinete como propone Negretto (2003: 66) en un estudio recién publicado. Sería más bien importante fortalecer los instrumentos de control de la minoría parlamentaria.

\section{EL APORTE DEL PARLAMENTO A LA CONSOLIDACIÓN Y A LA INSTITUCIONALIZACIÓN DE LA DEMOCRACIA}

Según los resultados presentados hasta ahora no hemos encontrado argumentos empíricos válidos que justifiquen la visión escéptica sobre el funcionamiento del sistema presidencial chileno. Hicimos hincapié en que los observadores escépticos explican la realidad opuesta a sus planteamientos con las circunstancias especiales de la transición democrática. Pero, ¿cuál ha sido el papel específico del Congreso en el proceso de transición y consolidación democrática?

Lamentablemente hay pocos estudios que enfocan de manera específica el tema del papel de los parlamentos en el proceso de consolidación democrática. Guiseppe Di Palma (1990: 39) propuso diferenciar entre el papel de los parlamentos como agentes en el proceso de consolidación democrática y como agentes-sujetos del desarrollo institucional del régimen democrático. Tal enfoque implica, a su vez, separar la consolidación de la democracia de su institucionalización. El planteamiento de una secuencia temporal de consolidación e institucionalización es discutible, tal vez sea más apropiado pensar en dos dimensiones que se separan por razones analíticas, pero que son simultáneas.

La consolidación -según Di Palma (1990)- se refiere a la creación de un consenso básico sobre las reglas del juego democrático y la disminución o desaparición del riesgo de una interrupción de la competencia democrática. Solamente después de ese punto, se puede decir que han echado raíces las funciones y rutinas institucionales, lo que incluye la socialización de las personas que actúan en el marco de las instituciones democráticas. 


\subsection{El aporte a la consolidación}

La politóloga Ulrike Liebert (1990: 15) se refiere en un estudio comparativo sobre Europa del Sur, a la diferenciación hecha por Di Palma (1990), enfocando especialmente los aportes del parlamento al proceso de consolidación democrática:

- La integración de las fuerzas políticas y sociales del país: las fuerzas del régimen anterior, así como también las nuevas y emergentes, y especialmente la potencial o actual oposición anti-sistémica.

- La estabilización de la regulación pacífica de los conflictos entre los actores políticos principales como condición para la capacidad de tomar decisiones y la gobernabilidad del nuevo régimen.

- La construcción de apoyos en la ciudadanía.

Respecto al último punto, se puede constatar empíricamente que el Congreso de Chile contaba ya con un alto respaldo por parte de la ciudadanía desde el inicio de la reinstauración de la democracia. Según un estudio de opinión pública de la Corporación Participa, en 1991 tres cuartos de los chilenos opinaron que la acción del Congreso fortalece a la democracia. Sin embargo, esta percepción inicial se difuminó y con el paso de los años aumentó el porcentaje de los encuestados que no percibieron ningún efecto o que no respondían. También bajó la percepción del grado de eficiencia del Congreso: al comienzo del gobierno de la Concertación, un 55 \% de los chilenos apreciaban que el Congreso funcionaba bien (ver Tabla 1). 
TABLA 1: Efecto percibido del Congreso sobre la democracia 1991-1994

Aporte al Fortalecimiento de la Democracia

\begin{tabular}{lrrrr}
\hline & 1991 & 1992 & 1993 & 1994 \\
\hline Fortalece & 75,8 & - & - & 55,1 \\
Debilita & 11,5 & - & - & 9,7 \\
No fortalece / ni debilita & 12,1 & - & - & 28,1 \\
NS/NR & 0,6 & - & - & 7,1 \\
\hline
\end{tabular}

Capacidad para ayudar a solucionar problemas

\begin{tabular}{lrrrr}
\hline Ayuda a solucionar & 71,5 & 51,1 & 52,3 & 42,8 \\
\hline & & & & \\
Funcionamiento del Congreso (\% muy de acuerdo/ de acuerdo) & & & \\
\hline El congreso está funcionando bien & 54,7 & 43,0 & 44,2 & 37,5 \\
$\begin{array}{l}\text { Los parlamentarios sólo se preocupan de la gente } \\
\text { en las elecciones }\end{array}$ & 54,8 & 74,7 & 74,1 & 74,9 \\
Tiene que haber más contacto entre la gente y el Congreso & 79,8 & 85,5 & 82,5 & 85,5 \\
A la gente como yo las leyes no les ayudan & 40,9 & 44,4 & 37,3 & 39,4 \\
\hline
\end{tabular}

Evaluación del trabajo de los diputados en el distrito electoral

\begin{tabular}{lcccc}
\hline Lo están haciendo bien & - & - & 19,7 & 17,1 \\
Lo están haciendo mal & - & - & 9,4 & 10,2 \\
Lo están haciendo regular & - & - & 46,9 & 45,0 \\
No sabe bien qué están haciendo & - & - & 20,3 & 23,5 \\
NS/NR & - & - & 3,7 & 4,3 \\
\hline
\end{tabular}

Representación de los intereses de los ciudadanos (diputados)

\begin{tabular}{lllrc}
\hline Representan & - & - & 36,4 & 31,1 \\
No representan & - & - & 43,5 & 50,8 \\
Los han perjudicado & - & - & 4,5 & 5,8 \\
NS/NR & - & - & 15,6 & 12,0 \\
\hline
\end{tabular}

Fuente: Garretón/Lagos/Méndez (1991-1994) 
A pesar de la evaluación en general positiva del aporte del Congreso al fortalecimiento de la democracia, desde el principio se manifestó un problema de representación que no se puede reducir a los enclaves autoritarios de la constitución. Ya en 1993, tres cuartos de los encuestados opinaron que los parlamentarios sólo se preocupan de la gente en las elecciones, menos de la quinta parte adjudicó a los diputados un buen trabajo y solamente poco más que un tercio de los consultados se sentía representado por los diputados.

El parlamento de Chile fue mucho más exitoso respecto a la integración de las fuerzas políticas y sociales principales y hasta cierto punto antagónicas del país y sobre la regulación pacífica de los conflictos. Las cámaras legislativas fueron el lugar privilegiado donde se integraron y/o fueron obligados a cooperar parte de la elite política del régimen autoritario, parte de la vieja elite política democrática de antes del golpe y algunos nuevos actores que se formaron en la lucha contra la dictadura. Una parte del éxito de las instituciones democráticas en Chile en los años noventa se debe a este acercamiento entre las fuerzas políticas antagónicas durante el régimen anterior. Ese proceso fue inducido por las necesidades de la transición y reforzado por los elementos no tan democráticos de la Constitución, como los Senadores institucionales, por ejemplo. Por eso, no estamos de acuerdo con la posición de algunos autores que perciben una incongruencia entre la sociedad chilena y sus instituciones políticas en los noventa y ven en este hecho un factor desestabilizador de la democracia (véase Siavelis, 2000a: 44). Se puede argumentar, más bien, que el relativo éxito de las instituciones políticas chilenas durante esa década se basa en parte en que, si bien no han sido un reflejo fiel de los ideales democráticos, han reflejado bien la relación de fuerza y poder en la sociedad. Retomando la argumentación de Liebert (1990), el Congreso fue justamente la arena donde las fuerzas políticas opuestas convivieron en el día a día, interactuaron en el proceso legislativo y a través de ese ejercicio de convivencia hicieron un aporte a la consolidación de la democracia.

\subsection{LA INSTITUCIONALIZACIÓN INTERNA: EL DESARROLLO TÉCNICO-PROFESIONAL DEL CONGRESO}

Si retomamos la línea de argumentación de Di Palma (1990) que propone una diferenciación analítica entre la consolidación y la institucionalización de la democracia y del parlamento, la institucionalización -según nuestra interpretación- tiene que ver con el cumplimiento de las funciones básicas adscritas a los parlamentos, a la vez de la aceptación de las reglas formales y de las reglas derivadas, como ya se mencionó. Además, para operar de una manera eficiente y dar sustento al régimen democrático -según sus atribuciones constitucionales y las funciones mencionadas- el Congreso tiene que desarrollar una capacidad técnico-profesional y socializar a sus miembros en ciertos patrones de comportamiento organizacional, puntos en los que el Congreso chileno hasta ahora ha sido bastante exitoso.

Según el estudio de John M. Carey (2002), en comparación con muchos otros parlamentos de América Latina en los años noventa el Congreso chileno tenía una tasa de reelección relativamente alta (alrededor de $60 \%$ en la Cámara y entre 44 y $50 \%$ en el Senado). En el Congreso constituido en 1997 un tercio de los diputados estaba en su primer periodo como legislador, otro tercio en el segundo y el último tercio en el tercero. En el Senado un $39 \%$ de los integrantes ya estaban en su 
segundo periodo y un $26 \%$ tenía experiencias anteriores como diputado. Entonces, se puede constatar en los pocos años de su existencia-después de un largo receso- que en el Congreso se han acumulado experiencias parlamentarias. Hay indicadores de una profesionalización de la política y para el desarrollo de una carrera parlamentaria. A las cifras citadas habría que añadir los parlamentarios con experiencia en dicha actividad antes de 1973, y los que ocuparon altos cargos de gobierno a lo largo de las últimas tres o cuatro décadas.

Además, otro indicador del desarrollo de capacidades profesionales consiste en una alta especialización y una gran continuidad en la composición de las comisiones parlamentarias, especialmente de las más importantes (Carey, 2002: 238-243). En nuestra encuesta a senadores en el 2002, el trabajo en comisiones fue evaluado muy positivamente, incluso un poco por encima de los otros países estudiados (Nolte, 2002: 21/22). Otros estudios indican que la asesoría legislativa y la infraestructura del Congreso chileno es mucho mejor que en la mayoría de los parlamentos latinoamericanos (véase Krumwiede y Nolte, 2000: 158-173), aunque no sea óptima y pueda ser mejorada. La misma encuesta del 2002 muestra que los diferentes servicios y estructuras de apoyo del Senado, como por ejemplo la Biblioteca del Congreso, la Oficina de Informaciones o algunos de los servicios de apoyo externo del trabajo parlamentario, fueron evaluados de una manera en general positiva (Nolte, 2002: 22). En conclusión, sólo nos queda coincidir con John M. Carey (2002: 253) que plantea: “... according to the standard criteria by which legislatures are compared, Chiles's Congress is reestablishing itself as an unusually professionalized and technically competent legislature."

\subsection{INSTITUCIONALIZACIÓN VERTICAL: LEGISLACIÓN Y CONTROL POLÍTICO}

Más allá del desarrollo de capacidades organizativas, la institucionalización de los parlamentos en el marco del desarrollo democrático tiene dos dimensiones: una horizontal referida a las relaciones del parlamento con los otros poderes del Estado y la cooperación a nivel de elites políticas, de lo que ya hemos discutido, y una integración vertical, que se refiere a la representación de los intereses y demandas de las no-elites (véase Liebert, 1995: 352). En la práctica política, la institucionalización horizontal se refleja en las clásicas funciones del parlamento de colegislar con el Presidente y controlar al Poder Ejecutivo. La vertical, a la vez, se refiere a la otra función clásica del parlamento de representar a los ciudadanos.

Con relación a la función de co-legislar hay que constatar que es muy difícil de evaluar la eficiencia del parlamento en base a su rendimiento legislativo. Si se toma el número de leyes queda pendiente la pregunta: ¿cuántas leyes son necesarias para cumplir con las demandas de los ciudadanos y arreglar los asuntos de la sociedad? Según cifras del propio Congreso citadas por Siavelis (2002: 86), durante el gobierno de Patricio Aylwin (1990-93) fueron despachadas en total 440 leyes (incluyendo iniciativas del Congreso), 110 en promedio por año ${ }^{21}$. Según otra estadística legislati-

21 Si se hace una comparación con Argentina en los mismos años (1990-1993) fueron sancionados en promedio 135 por año (y en los primeros cuatro años de la democracia (1984-1987) fueron 126) (Molinelli et al., 1999: 418-419). 
va (Cortés, 1998) ${ }^{22}$ entre 1990 y 1998 fueron promulgados y publicados en el diario oficial 857 leyes y acuerdos internacionales, eso implica 95 leyes por año ${ }^{23}$.

En cambio, si se toma como indicador de eficiencia el tiempo que dura el proceso legislativo cabe preguntarse cuál puede ser el tiempo óptimo, ya que un procesamiento demasiado rápido puede resultar apresurado y llevar a errores, a la vez que demasiado tiempo puede influir en lo oportuna que resulte la medida adoptada. Por otro lado, hay que incluir otras variables como las mayorías incongruentes de las cámaras, que pueden dilatar el proceso, sin que esto implique que la ley pierda en calidad.

Debido a la dificultad de medir y evaluar la eficiencia legislativa, vamos a presentar solamente algunas reflexiones preliminares. Según la constitución chilena, el presidente tiene el derecho exclusivo de introducir la legislación en varias áreas de políticas públicas. Además, la mayoría de los sistemas presidenciales latinoamericanos se acerca ahora a la práctica de los sistemas parlamentarios, en los que el Ejecutivo elabora e introduce la mayor parte de la legislación. Partiendo del supuesto que éste hace un cierto cálculo de las posibilidades de éxito de sus propuestas y que toma en cuenta las mayorías en las cámaras y la opinión de las bancadas que le apoyan, la tasa de éxito de las iniciativas del Poder Ejecutivo puede ser tomada como indicador de la eficiencia legislativa del Congreso. Solamente en parte puede esto servir como un indicador para medir la preponderancia de éste.

Durante el gobierno de Patricio Aylwin (1990-93) un total de 63,4 por ciento de las iniciativas presidenciales se convirtieron en ley (Siavelis, 2002: 86). Si tomamos la presidencia de Eduardo Frei Ruiz-Tagle (1994-2000), de los 495 mensajes presentados por el gobierno, 64,7 \% (314) se convirtieron en ley (Libertad y Desarrollo, 2000). Esa tasa de éxito de las iniciativas del Poder Ejecutivo de alrededor de un poco menos de dos tercios se puede interpretar como que el Congreso (o la mayoría parlamentaria) ha funcionado bastante bien en su función de colegislar con el presidente, pero sin convertirse en un actor pasivo y puro receptor de las iniciativas presidenciales. Habría que estudiar la razones por qué fueron rechazadas o retiradas las iniciativas legislativas del Presidente para perfeccionar este primer acercamiento al tema de la eficiencia legislativa.

El control parlamentario tiene la función de hacer transparentes los procesos de decisión política para que una ciudadanía informada, crítica y reflexiva pueda participar en la discusión sobre las políticas del gobierno y las posiciones de los actores parlamentarios. Desde un enfoque más técnico, tal control se define como el proceso parlamentario de revisar y determinar (e influir en) el comportamiento de otros actores e instituciones (especialmente del gobierno y de la administración pública) con la capacidad de sancionar de manera directa (por la mayoría parlamentaria) 0 indirecta (por la oposición) las actividades de los mismos (véase Steffani, 1989: 1328). 0 expresado más brevemente, el control parlamentario se define como la capacidad de revisar y sancio-

22 En el marco de ese artículo no fue posible aclarar las diferencias cuantitativas respecto al rendimiento legislativo según las diferentes fuentes.

23 Para tener otras cifras de referencia: entre 1925 y 1968 fueron despachadas en Chile en promedio 300 leyes por año, pero más de la mitad se refirieron a asuntos de gracia (Valenzuela y Wilde, 1979: 195/201). Para tomar otro ejemplo en Alemania entre 1980 y 1994 en promedio fueron sancionadas 89 leyes por año (Schindler, 2000). 
nar las actuaciones del gobierno y de la administración pública. Normalmente, no es el parlamento en su conjunto el que cumple con esta función, sino la oposición parlamentaria.

Pero, en muchas áreas de control, la oposición necesita la aquiescencia de la mayoría parlamentaria como, por ejemplo, para la formación de una comisión investigadora, para adoptar acuerdos, sugerir observaciones al presidente o para iniciar una acusación política a integrantes del Poder Ejecutivo. Eso explica, entre otras cosas, por qué el oficio de fiscalización, que necesita el apoyo de la mayoría parlamentaria, hasta ahora fue poco usado (véase los datos en Siavelis, 2000b: 86). También las comisiones investigadoras funcionan según la lógica de mayoría-minoría parlamentaria desde su creación, hasta su composición y los resultados (informes finales y seguimiento parlamentario ${ }^{24}$. Es más fácil para la oposición emplear las atribuciones del Parlamento de poder obligar al gobierno a dar cuenta de sus actividades de manera pública e iniciar un debate abierto sobre las mismas con la posibilidad de influir en la opinión ciudadana con miras a una eventual sanción electoral.

Como rasgo específico de la Constitución chilena, las atribuciones fiscalizadoras -en el sentido estricto- se limitan a la Cámara de Diputados. Cualquier diputado con el voto favorable de un tercio de los miembros presentes en la Cámara puede mandar un oficio al Gobierno para solicitar determinados antecedentes; pero existen pocas informaciones sobre el uso y efecto de ese instrumento de control político. Durante la presidencia de Patricio Aylwin fueron presentados 18.532 oficios y se respondieron alrededor de 14.700, es decir, más o menos el 80 \% (Siavelis, 2000a: 29). No hay investigaciones acerca del impacto de esos oficios, ni contamos con una base de datos para comparar el Congreso chileno con otros parlamentos latinoamericanos ${ }^{25}$.

\subsection{INSTITUCIONALIZACIÓN VERTICAL: REPRESENTACIÓN}

Si tomamos el modelo de Schmitter (1992: 428) que diferencia distintos regímenes parciales en el proceso de consolidación democrática, el parlamento forma parte de, por lo menos, cuatro regímenes parciales: el constitucional, el representativo (que lo vincula con la ciudadanía), el electoral (que lo vincula con los partidos) y el de grupos de presión. Por razones analíticas, tiene sentido diferenciar entre el régimen constitucional u horizontal, por un lado, que ya hemos analizado desde diversos ángulos, y el régimen representativo que, según nuestra opinión, incluye diferentes sub-regímenes. El Congreso constituye, de cierta manera, un nudo para diferentes redes para la representación de intereses organizados (véase Liebert, 1995: 191/203) y los ciudadanos en su conjunto.

¿Representa el Congreso chileno a los ciudadanos y ciudadanas? Desde el lado de la oferta del Parlamento chileno y tomando como criterio la auto-ubicación de los parlamentarios en una escala

24 Según informaciones del Congreso chileno resumidas por Siavelis (2000b: 87) entre marzo de 1990 y abril 1998 fueron creadas 35 comisiones de investigación, de las cuales hasta abril 1998 un total de siete todavía no se constituyeron, tres terminaron sin un informe final, en dos casos el informe estaba pendiente, 13 presentaron informe final, pero que no fue objeto de un debate parlamentario, y solamente diez presentaron un informe que tambíen fue discutido en el pleno.

25 Para tener una cifra de referencia en el Deutsche Bundestag, que cuenta con cinco veces más diputados, en los años 1990-1994 fueron presentadas 16.665 solicitudes de preguntas escritas (schriftliche Anfragen) por los diputados, sin tomar en cuenta las presentadas por bancadas (Schindler, 2000). Para cifras del Congreso argentino ver Molinelli et al. (1999: 508-511). 
de izquierda a derecha, se observa que los senadores y diputados representan un amplio espectro ideológico desde centro-izquierda hasta posiciones de centro-derecha. En el caso de los primeros fue posible, además, comprobar que la auto-evaluación tiene que ver con posiciones divergentes en la cuestión sobre la conveniencia de una mayor o menor supervisión del Estado sobre el mercado (véase Nolte y Sánchez, 2003). Diversidad que a priori haría pensar que se cubren las diferentes posiciones político-ideológicas de la sociedad.

TABLA 2: Ubicación ideológica de los partidos chilenos según sus representantes en la Cámara de Diputados y en el Senado (media aritmética por partido) (1 izquierda - 10 derecha)

\begin{tabular}{lccccc}
\hline & PS & PPD & PDC & RN & UDI \\
\hline Cámara 1994 & 2,93 & 4,36 & 4,40 & 6,36 & 6,80 \\
Cámara 1998 & 2,50 & 4,00 & 4,83 & 6,76 & 8,18 \\
Cámara 2002 & 2,56 & 3,85 & 5,28 & 6,80 & 7,08 \\
Senado 2002 & 2,00 & 4,33 & 5,63 & 7,00 & 7,44 \\
\hline
\end{tabular}

Fuente: Elaboración propia a partir de los datos de las investigaciones: Elites parlamentarias, de la Universidad de Salamanca, y Los senados en el Cono Sur, del IIK- Hamburgo.

Pero retomando la pregunta: ¿Se consideran los ciudadanos representados por el Congreso y valoran su rendimiento? Y contrastándola con otros datos, parece que a pesar del alto grado de institucionalización horizontal y de profesionalización, los ciudadanos no aprecian el trabajo del Congreso y no tienen confianza en sus parlamentarios. Si tomamos los resultados de las encuestas de opinión pública como indicadores, hay que constatar que la integración vertical entre ciudadanos y Congreso es deficiente ${ }^{26}$. Las encuestas del CERC, que miden la confianza en la institución Congreso y de sus integrantes desde mediados de los años noventa, documentan un descenso fuerte en el apoyo para la cámara de Diputados y el Senado ${ }^{27}$. Además, en el 2002, solamente un $39 \%$ de los chilenos opinaron que les afectan las decisiones del Congreso; más de la mitad (54 \%) dijo que las decisiones que se toman en él les afectan "poco" o "nada". tan mal evaluado. Sin embargo, hay que constatar que los datos del Latinobarómetro revelan un apoyo mucho más alto que las encuestas nacionales, las que se refieren solamente a Chile. Según los datos del Latinobarómetro en 1998 40\% de los encuestados chilenos tenían mucha o algo de confianza en el Congreso, en comparación con $27 \%$ en el promedio latinoamericano; esta confianza bajó en 2001 a un tercio (33\%) y 24\% en el promedio latinoamericano (Lagos 1999: 44; informes de prensa http://www.latinobarometro.org). No es objetivo de este estudio explicar las variaciones entre los resultados de las diferentes encuestas de opinión pública realizadas en Chile.

27 En los úlltimos cuatro años, un promedio de un $80 \%$ de los entrevistados estaba solamente "algo satisfecho" o "no muy satisfecho" con la labor del Senado o de la Cámara de Diputados (CERC 2002: 12). 
TABLA 3: Confianza en instituciones y elites parlamentarias 1996-2002 (suma de "mucha" y "bastante" confianza en porcentaje)

\begin{tabular}{lcccc}
\hline & Senado & Cámara & Senadores & Diputados \\
\hline 1996 & 27 & 26 & 28 & 27 \\
1997 & 20 & 20 & 20 & 20 \\
1998 & 20 & 21 & 23 & 22 \\
1999 & 15 & 15 & 16 & 17 \\
2000 & 21 & 22 & 26 & 24 \\
2001 & 12 & 12 & 16 & 17 \\
2002 & 12 & 11 & 14 & 12 \\
Promedio & 18 & 18 & 20 & 20 \\
\hline
\end{tabular}

Fuente: CERC (2002: 9-11)

¿Cuál puede ser la explicación para la disminución del apoyo de los ciudadanos al Congreso, una disminución que también se manifiesta en un número creciente de ciudadanos jóvenes no inscritos en los registros electorales? Una explicación puede hacer hincapié en los "enclaves autoritarios" (senadores institucionales, Consejo Nacional de Seguridad, etc.). Esto parece en realidad poco convincente, porque

- $\quad$ también en otros países latinoamericanos sin enclaves autoritarios se observa una pérdida de confianza en los parlamentos;

- $\quad$ no todas las instituciones políticas (Presidente, Poder Judicial, etc.), las que también son afectadas por los enclaves autoritarios, sufren la misma disminución de apoyo;

- la confianza en el Congreso fue más alta a principio de los noventa, cuando la influencia de los enclaves autoritarios era mayor que ahora.

Un análisis más amplio de las encuestas de opinión puede arrojar otra pista para explicar el bajo apoyo al Congreso. Los datos muestran que todas las estructuras de articulación y agregación de intereses sociales cuentan con poco apoyo y poca confianza entre los ciudadanos, lo que hace pensar en una crisis generalizada del régimen representativo y sus subsistemas, donde se incluyen, además del Congreso, a los partidos políticos, el sistema electoral (considerando los mecanismos de inscripción y el voto obligatorio), y organizaciones profesionales, sindicales y empresariales.

\section{CONCLUSIONES}

Nuestro estudio se ha basado, principalmente, en los resultados de las investigaciones empíricas y conceptuales de varios investigadores chilenos y extranjeros a los que hemos añadido algunos pequeños aportes propios. De todo esto, como conclusiones se puede compendiar lo siguiente: 
- El éxito del sistema político se basa en la apropiación paralela de las reglas escritas y de las reglas derivadas o implícitas del juego político.

- $\quad$ En Chile se ha consolidado un sistema presidencial, con un presidente fuerte según sus atribuciones constitucionales, pero más fuerte en sus poderes legislativos reactivos que en sus poderes pro-activos.

- $\quad$ Los poderes del Presidente son atenuados por el hecho de tratarse de un sistema presidencial con un sistema multipartidario que solamente funciona de una manera estable si se constituye un presidencialismo de coalición que implica, a su vez, una coordinación estrecha entre los objetivos del presidente y de las bancadas que forman parte de su coalición de gobierno.

- $\quad$ El Presidente cuenta con amplios poderes de agenda que son compatibles y útiles para un presidencialismo de coalición que funciona según la lógica de partidos de gobierno versus partidos de oposición, con una mayoría parlamentaria a lo menos en una de las dos cámaras. En ese sentido, se puede hablar de una cierta "parlamentarización" del presidencialismo chileno.

- $\quad$ Debido a la estructuración del juego parlamentario, según la lógica gobierno/mayoría parlamentaria versus minoría/oposición parlamentaria, son muy importantes las facultades de control que pueda ejercer la oposición.

- $\quad$ Los poderes del Presidente son mitigados también por el hecho que el Congreso ha logrado un alto grado de profesionalización y de capacidad técnica. A pesar que como en todas las democracias -salvo tal vez el sistema norteamericano- todavía existe un desnivel sumamente grande entre la burocracia estatal al servicio del Poder Ejecutivo y los servicios de apoyo del Poder Legislativo.

- El Congreso ha alcanzado una institucionalización organizativa y horizontal alta. Además, ha aportado al proceso de la consolidación de la democracia como instancia de integración entre las elites políticas del régimen autoritario y las elites democráticas de antes de 1973 o formadas durante la dictadura.

- $\quad$ Los éxitos en la institucionalización horizontal no se reflejan en la institucionalización vertical. Se manifiesta un problema de representación, que tiene que ver con las deficiencias de las estructuras de intermediación que a su vez interactúan con el Parlamento.

A pesar de las advertencias escépticas mencionadas al comienzo de nuestra presentación, por el momento no se proyectan elementos para un cambio de la lógica del sistema presidencial chileno a corto plazo, independiente del desenlace de las elecciones a fines del 2005. Para nosotros el buen rendimiento y funcionamiento del sistema presidencial no constituye ninguna paradoja; la contradicción resulta de un enfoque institucionalista demasiado rígido y limitado. Para nosotros, la singularidad se constituye porque tenemos en Chile un Parlamento que ha logrado una institucionalización horizontal bastante exitosa -aunque siempre hay posibilidades de una mejora-, que ha aportado a la consolidación democrática respecto a la integración de los elites, pero que en la percepción de los ciudadanos no ha logrado una institucionalización vertical satisfactoria. 


\section{REFERENCIAS}

Abranches, Sérgio Henrique H. 1988. "Presidencialismo de Coalizão: 0 Dilema Institucional Brasileiro". Dados. Revista de Ciências Sociais 31(1): 8-34.

Agor, Weston. 1971a. The Chilean Senate. Internal Distribution of Influence. Austin/London: University of Texas Press.

Agor, Weston (ed.). 1971b. Latin American Legislatures: Their Role and Influence. Analyses for Nine Countries. New York: Praeger.

Altman, David. 2000. "The Politics of Coalition Formation and Survival in Multi-Party Presidential Democracies. The Case of Uruguay, 1989-1999". Party Politics 6 (3): 259-283.

Altman, David y Aníbal Pérez-Liñán. 2002. "Assessing the Quality of Democracy: Freedom, Competitiveness and Participation in Eighteen Latin American Countries". Democratization 9 (2): 85-100.

BID 2000. Desarrollo más allá de la economía: Informe de progreso económico y social en América Latina. Washington D.C.: BID. Carey, John M. 2002. "Parties, Coalitions, and the Chilean Congress in the 1990s". En Morgenstern y Nacif (2002: 222-253).

Carey, John M. y Matthew Soberg Shugart(eds.). 1998. Executive Decree Authority. Cambridge: Cambridge University Press. Carey, John M. y Peter Siavelisr. 2003. "El 'seguro' para los subcampeones electorales y la sobrevivencia de la Concertación”. Estudios Públicos 90: 5-27.

Chasquetti, Daniel. 2002. "Democracia, Multipartidismo y Coaliciones en América Latina. Evaluando la Difícil Combinación". Lateinamerika Analysen 3: 67-92.

CERC. 2002: Informe de prensa sobre temas económicos y políticos. Santiago de Chile.

Cortés, Raúl. 1998. "Informe sobre la actividad legislativa en 1998". Serie Opinión N 12. Santiago de Chile: Libertad y Desarrollo.

Cox, Gary W. y Scott Morgenstern. 2002. "Epilogue: Latin America's Reactive Assemblies and Proactive Presidents". En Morgenstern y Nacif (2002: 446-468).

Crisp, Brian F. 1998. "Presidential Decree Authority in Venezuela". En Carey y Shugart (1998: 142-174).

Deheza, Grace Ivana. 1998. "Gobiernos de coalición en el sistema presidencial: América del Sur". En Nohlen y Fernández (1998: 151-169).

Di Palma, Guiseppe. 1990. "Parliaments, consolidation, institutionalisation: a minimalist view". En Liebert y Cotta (1990: 31-51).

Döring, Herbert. 1995. "Time as Scarce Resource: Government Control of the Agenda". En Parliaments and Majority Rule in Western Europe, editado por Herbert Döring. Frankfurt y New York: Campus, 223-246.

Döring, Herbert. 2001. "Parliamentary Agenda Control and Legislative Outcomes in Western Europe". Legislative Studies Quarterly 26 (1): 145-165.

Drago, Mario. 2002. "Coordinación de las Oficinas de la Presidencia y de las Relaciones Interministeriales". En Reforma y modernización del Estado. Experiencias y desafíos, editado por Luciano Tomassini y Marianela Armijo. Santiago de Chile: LOM, 59-104.

Fernández, Mario. 1998. "El sistema político chileno. Características y tendencias". En Chile en los noventa, editado por Cristián Toloza y Eugenio Lahera. Santiago de Chile: Dolmen, 27-52.

Ferreira, Rubio Delia. 1998. "When the President Governs Alone: The Decretazo en Argentina, 1989-93". En Carey y Shugart (1998: 33-61).

Frei, Eduardo et al. 1970. Reforma Constitucional 1970. Santiago de Chile: Editorial Jurídica.

Foweraker, Joe, Todd Landmann, y Neil Harvey. 2003. Governing Latin America. Cambridge: Polity Press.

Garretón, Manuel Antonio, Marta Lagos y Roberto Méndez. 1991-1994. Los Chilenos y la Democracia. La opinión pública 1991-1994. 4 tomos. Santiago de Chile: Ed. Participa.

Gil, Federico. 1966. The Political System of Chile. Boston: Houghton Mifflin Company.

Krumwiede, Heinrich-W. y Detlef Nolte 2000. Die Rolle der Parlamente in den Präsidialdemokratien Lateinamerikas. Hamburg: Institut für Iberoamerika-Kunde (Beiträge zur Lateinamerikaforschung No.4).

Lagos, Marta. 1999. “Quo vadis, América Latina? El estudio de la opinión pública regional en el Latinobarómetro”. Contribuciones $16(2): 31-54$. 
Lanzaro, Jorge. 1998. "Uruguay: Las alternativas de un presidencialismo pluralista”. Revista Mexicana de Sociología 60(2): 187-218.

Libertad y Desarrollo. 2000. "Balance Legislativo Período Presidencial 1994-2000". Temas Públicos 483.

Liebert, Ulrike. 1990. "Parliament as a central site in democratic consolidation: a preliminary exploration". En Liebert y Cotta (1990: 3-30).

Liebert, Ulrike y Maurizio Cotta(eds.). 1990. Parliament and Democratic Consolidation in Southern Europe: Greece, Italy, Portugal, Spain and Turkey. London: Pinter Publishers.

Liebert, Ulrike. 1995. Modelle demokratischer Konsolidierung. Parlamente und organisierte Interessen in der Bundesrepublik Deutschland, Italien und Spanien (1948-1990). Opladen: Leske + Budrich.

Limongi, Fernando y Argelina Figueiredo. 1998. "Bases institucionais do presidencialismo de coalizão". Lua Nova. Revista de Cultura e Política 44: 81-106.

Linz, Juan. 1994. "Presidential or Parliamentary Democracy: Does it Make a Difference?". En Linz y Valenzuela (1994: 3-87).

Linz, Juan. 1996a. "The Perils of Presidentialism". En The Global Resurgence of Democracy, editado por Larry Diamond y Marc

F. Plattner. 2. edición. Baltimore/London: Johns Hopkins University Press, 124-142.

Linz, Juan. 1996b. "The Virtues of Parliamentarism". En The Global Resurgence of Democracy, editado por Larry Diamond y Marc F. Plattner. 2. edición. Baltimore/London: Johns Hopkins University Press, 154-161.

Linz, Juan y ArturoValenzuela (eds.). 1994. The Failure of Presidential Democracy. 2 tomos, Baltimore/London: Johns Hopkins University Press.

Mainwaring, Scott. 1993. "Presidentialism, Multipartism, and Democracy. The Difficult Combination". Comparative Political Studies 26 (2): 198-228.

Mainwaring, Scott y Matthew SobergShugart (eds.). 1997. Presidentialism and Democracy in Latin America. Cambridge/New York: Cambridge University Press.

Metcalff, Lee Kendall. 2000: "Measuring Presidential Power". Comparative Political Studies 33 (5): 660-685.

Molinelli, Guillermo, Valeria Palanza y Gisela Sin. 1999. Congreso, Presidencia y Justicia en Argentina. Buenos Aires: Temas. Morgenstern, Scott. 2002. "Explaining Legislative Politics in Latin America”. En Morgenstern y Nacif (2002: 413-445).

Morgenstern, Scott y Benito Nacif (eds.). 2002. Legislative Politics in Latin America. Cambridge: Cambridge University Press. Mustapic, Ana María. 2002. "Oscillating Relations: President and Congress in Argentina". En Morgenstern y Nacif (2002: 23-48).

Negretto, Gabriel L.. 2003. “Diseño constitucional y separación de poderes en América Latina”. Revista Mexicana de Sociología 65 (1): $41-76$

Nino, Carlos Santiago. 1992. Fundamentos de Derecho constitucional. Análisis filosófico, jurídico y politológico de la práctica constitucional. Buenos Aires.

Nohlen, Dieter. 2003. El contexto hace la diferencia: reformas institucionales y el enfoque histórico-empírico. México: Universidad Autónoma.

Nohlen, Dieter y Mario Fernández (eds.). 1998. El presidencialismo renovado. Instituciones y cambio político en América Latina. Caracas: Nueva Sociedad.

Nolte, Detlef. 1999. "Alianzas electorales y coaliciones de gobierno como símbolos del cambio político en América Latina". Revista Argentina de Ciencia Política 3: 11-26.

Nolte, Detlef. 2000. "La reforma del presidencialismo y el fortalecimiento de los parlamentos". En Democracia y Estado Social de Derecho, editado por Ulrich Laute y Jairo A. Morales. Bogotá: Fundación Konrad Adenauer/Celam, 177-232.

Nolte, Detlef. 2002. Radiografía del Senado de Chile: informe de la encuesta 2002. Hamburgo: Institut für IberoamerikaKunde (Arbeitspapier № 8)

Nolte, Detlef y Francisco Sánchez. En prensa 2003. "El Senado chileno: pautas de representación política y perfil ideológico". Anuario FLACSO 2003, Santiago de Chile: FLACSO.

Payne, J. Mark, Daniel Zovatto, Fernando Carrillo Flórez y Andrés Allamand. 2003. La política importa. Democracia y desarroIlo en América Latina. Washington D.C: BID

O’Donnell, Guillermo. 1992. "Delegative Democracy?" Kellog Institute, University of Notre Dame, Working Paper 172. 
Rehren, Alfredo. 1992. "Liderazgo presidencial y democratización en el Cono Sur de América Latina". Revista de Ciencia Política 14 (1): 63-87.

Rehren, Alfredo. 1993. "La Presidencia en el gobierno de la Concertación". Estudios Sociales 75: 15-38.

Samuels, David J. y Matthew Soberg Shugart. 2003. "Presidentialism, Elections and Representation". Journal of Theoretical Politics 15 (1): 33-60.

Schindler, Peter. 2000. Datenhandbuch zur Geschichte des Deutschen Bundestages 1949-1999. Berlin: Deutscher Bundestag (CD-Rom).

Schmitter, Philippe. C. 1992. "The Consolidation of Democracy and Representation of Social Groups". American Behavioral Scientist 35 (4/5): 422-449.

Shugart, Matthew Soberg y John L. Carey. 1992. Presidents and Assemblies. Constitutional Design and Electoral Dynamics. Cambride/New York: Cambridge University Press.

Shugart, Matthew Soberg y Stephan Haggard. 2001. "Institutions and Public Policy in Presidential Systems". En Presidents, Parliaments and Policy, editado por Stephan Haggard y Mathew D. McCubbins. Cambridge: Cambridge University Press, 64-104.

Siavelis, Peter. 2000'. The President and Congress in Postauthoritarian Chile. Institutional Constraints to Democratic Consolidation. University Park, PA: The Pennsylvania State University Press.

Siavelis, Peter. 2000b. "Disconnected Fire Alarms and Ineffective Patrols: Legislative Oversight in Postauthoritarian Chile". Journal of Interamerican Studies and World Affairs 42 (1): 71-98.

Siavelis, Peter. 2002. "Exaggerated Presidentialism and Moderate Presidents: Executive-Legislative Relations in Chile". En Morgenstern y Nacif (2002: 79-111).

Steffani, Winfried. 1989. "Formen, Verfahren und Wirkungen parlamentarischer Kontrolle". En Parlamentsrecht und Parlamentspraxis, editado por Hans-Peter Schneider y Wolfgang Zeh. Berlin/New York: de Gruyter, 1325-1367.

Thibaut, Bernhard. 1998. "El gobierno de la democracia presidencial: Argentina, Brasil, Chile y Uruguay en una perspectiva comparada". En Nohlen y Fernández (1998: 127-150).

Tsebelis, George. 2002. Veto Players. How Political Institutions Work. Princeton: Princeton University Press.

Valenzuela, Arturo. 1976. "Political Constraints to the Establishment of Socialism in Chile". En Chile: Politics and Society, editado por Arturo Valenzuela y J. Samuel Valenzuela. New Brunswick: 1-29.

Valenzuela, Arturo. 1993. "Latin America: Presidentialism in Crisis". Journal of Democracy 4 (4): 3-16.

Valenzuela, Arturo. 1994. "Party Politics and the Crisis of Presidentialism in Chile: A Proposal for a Parliamentary Form of Government". En Linz y Valenzuela (1994II: 91-150).

Valenzuela, Arturo y Alexander Wilde. 1979. "Presidential Politics and the Decline of the Chilean Congress". En Legislatures in Development: Dynamics of Change in New and Old States, editado por Joel Smith y Lloyd D. Musolf. Durham: Duke University Press, 189-215.

Detlef Nolte. Doctor en Ciencia Política (Universität Mannheim 1986); actualmente es subdirector del Instituto de Estudios Iberoamericanos en Hamburgo y profesor en Ciencia Política y Estudios Latinoamericanos en la Universidad de Hamburgo; Miembro del Comité Ejecutivo de la Asociación Latinoamericana de Ciencia Política; autor de varios libros y cerca de ochenta artículos sobre sistemas políticos, relaciones internacionales y otros temas vinculados con América Latina. Entre otros: Die Rolle der Parlamente in den Präsialdemokratien Lateinamerikas (junto con Heinrich-W. Krumwiede), Hamburg: IIK 2000. "Bicameralism in the Americas: Around the Extremes of Symmetry and Incongruence" (junto con Mariana Llanos), que se publica en: Journal of Legislative Studies 9 (2003) 3.

(E-mail: nolte@iik.duei.de) 